\title{
Microstructure and Mechanical Properties of AA6061/AZ31B/AA6061 Composite Plates Fabricated by Vertical Explosive Welding and Subsequent Hot Rolling
}

\author{
Wen-wu Yang ${ }^{a, b}{ }^{\circledR}$, Xiao-qing Cao ${ }^{a, b *}$, Li-fei Wang ${ }^{a, b}$, Zhi-qing Chen ${ }^{a, b}$, Wen-xian Wang ${ }^{a, b}$, \\ Dong-ya Wang ${ }^{a, b}$ \\ ${ }^{a}$ Shanxi Key Laboratory of Advanced Magnesium-Based Materials, Taiyuan 030024, China \\ ${ }^{b}$ College of Materials Science and Engineering, Taiyuan University of Technology, Taiyuan 030024, \\ China
}

Received: May 16, 2018; Revised: August 17, 2018; Accepted: August 24, 2018

In this study, three-ply $\mathrm{Al} / \mathrm{Mg} / \mathrm{Al}$ composite plates were successfully achieved by vertical explosive welding (EXW) method. After EXW, the sound joints were obtained. Then thin three-ply Al/Mg/Al EXWed composite plates with the thickness of $1.78 \mathrm{~mm}$ were achieved by hot rolling. The influence of annealing on the interface microstructures and mechanical properties of the thin composite plates was investigated. The results indicated that different morphology with big waveform and mini waveform was present in the explosively bonded interface. The interface shear strength was $91 \mathrm{MPa}$ for big waveform side and 92Mpa for mini waveform side. The rolled sample without annealing possessed the high ultimate tensile strength (UTS) value of $235 \mathrm{Mpa}$ and elongation of $8.5 \%$. The equiaxed and homogeneous grain morphology of magnesium alloys in the thin three-ply $\mathrm{Al} / \mathrm{Mg} / \mathrm{Al}$ composite plates could be induced by annealing $300^{\circ} \mathrm{C}$ for $1 \mathrm{~h}$. This contributed to the considerable increase of elongation by $18.5 \%$.

Keywords: Explosive welding, Rolling, Al/Mg/Al composite plates, Interface microstructures, Mechanical properties.

\section{Introduction}

With an increasing demand of particularity and multifunctionality of materials, the hybrid materials which could achieve the combination of merits of two or more materials have been paid wide attention ${ }^{1}$. In the fabricating process of hybridization, a large amount of effective structures such as fibre composites ${ }^{2}$, foams ${ }^{3}$, lattice structures ${ }^{4}$ and multilayered structures ${ }^{5}$ have been achieved. Among them, multilayered structures are regarded as the simple and low cost-effective approach for hybrid materials designing.

Metal composite plates which consist of two or more dissimilar metallic alloys is a vital type of multilayered structures. Comparing with monolayer plates, the metal composite plates possess special capabilities such as corrosionresistance, high mechanical and thermal properties, et al. From now on, the fabrication of metal composites has been carried out through numerous kinds of processes such as $\mathrm{EXW}^{6-9}$, diffusion bonding ${ }^{10,11}$, fusion welding ${ }^{12}$, resistance seam cladding ${ }^{13}$ and roll bonding ${ }^{14-17}$. Due to considerable advantages such as high bond strength, EXW is becoming an increasingly popular method of joining. Findik ${ }^{9}$ has given a detail summary of the development of EXW. As a solid-state welding technique, the generation and growth of intermetallic compound (IMC) layers at interface could be effectively depressed by EXW process. Kahraman et al. ${ }^{18}$ showed no

*e-mail: cxqty@126.com. indication of any crack separation and tear at interface in Ti-6Al-4V/Al explosively welded composite plates.

The choice of metallic alloys is crucial to the ideal metal composites by EXW. Due to the advantages of ultra-low density and high specific strength, magnesium alloys are applied in automotive, aerospace and household appliances. However, the deformation of most of magnesium alloys is coordinated by activation of twinning and slip only on basal planes at room temperature ${ }^{19}$. In addition, magnesium alloys are easily corroded through the formation of galvanic corrosion due to their highly negative standard electrode potential ${ }^{20}$. So there are two intrinsic drawbacks, poor formability and poor corrosion resistance at room temperature, which restrict the applications of magnesium alloys. In order to widen the application of magnesium alloys, it is necessary to fabricate the composites by cladding magnesium alloys with other alloys which possess good formability and corrosion resistance. These structures enable combinations of selective properties such as good formability, high strength and good corrosion from the constituent metallic alloys. Comparing with many metallic alloys that can act as cladding materials, like copper ${ }^{21}$, titanium ${ }^{22}$ and stainless steel ${ }^{17}$, lightweight aluminum alloys with good corrosion resistance have been widely taken into consideration $^{23,24}$. In this regard, the EXW process could fabricate $\mathrm{Al} / \mathrm{Mg}$ composites with the advantage of combination of corrosion-resistance and high specific strength. Yan et al..$^{25}$ showed that the shear strength of AZ31B/7075 composite plates was approximately $70 \mathrm{MPa}$ and the maximum bending 
stress of $670 \mathrm{MPa}$. Zhang et al. ${ }^{7}$ revealed that the $\mathrm{Al} / \mathrm{Mg}$ composite plates bonded well due to the formation of thin diffusion layer. However, the EXW for fabrication of thin composite plates is not merely challengeable but expensive. The roll-bonding process is the most widely used technique owing to the cost-effective continuous fabrication on thin composite plates ${ }^{24}$. Wang et al. ${ }^{8}$ investigated the influence of hot rolling on the interface microstructures and mechanical properties of explosively welded $\mathrm{Mg} / \mathrm{Al}$ composite plates, which indicated that hot rolling conduced to improve the tensile strength and elongation of composite plates. Therefore, in order to achieve thin composite plates with high bonding strength and considerable plasticity, combination of EXW and roll-bonding is feasible.

Up to now, most studies on $\mathrm{Al} / \mathrm{Mg}$ composite plates fabricated by EXW process have been focused on two-ply composite plates. Few studies on three-ply explosive-welded $\mathrm{Al} / \mathrm{Mg} / \mathrm{Al}$ composite plates with better corrosion resistance were reported ${ }^{24}$. Additionally, a parallel layers arrangement was commonly used for experimental setup of EXW process, which leads to heterogeneous plastic deformation at top and bottom interface. In this paper, the vertical EXW for the fabrication of three-ply $\mathrm{Al} / \mathrm{Mg} / \mathrm{Al}$ composite plates was applied to obtain relatively uniform structures. Besides, the process of EXW which was conducted in the sinkhole is highly in safety. Subsequently, the thin $\mathrm{Al} / \mathrm{Mg} / \mathrm{Al}$ composite plates with high bonding strength and better plasticity were fabricated by the process of EXW united with hot rolling. Furthermore, annealing was performed to achieve good combination of interface microstructures and mechanical properties of the thin EXWed-rolled composites.

\section{Experimental}

In this study, aluminum (AA6061)/magnesium (AZ31B)/ aluminum (AA6061) composite plates were fabricated by EXW in one stage. The vertical plate cladding arrangement in sinkhole was used as shown in Figure 1.

The magnesium plates and aluminum plates were vertically placed in $\mathrm{Al} / \mathrm{Mg} / \mathrm{Al}$ in the willow fixture by order. The dimensions of AZ31B and AA6061 plates used in this study were $600 \mathrm{~mm} \times 300 \mathrm{~mm} \times 10 \mathrm{~mm}$ and $650 \mathrm{~mm} \times 350$

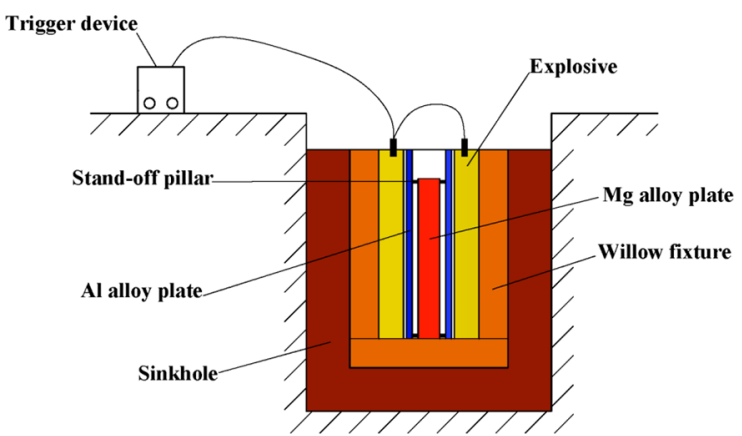

Figure 1. Experimental setup of vertical explosive welding process. $\mathrm{mm} \times 2 \mathrm{~mm}$, respectively. The chemical compositions of the materials used are given in Table 1. The AMATOL powder was used as explosive with a velocity of detonation equal to $2500 \mathrm{~m} / \mathrm{s}$ and density equal to $800 \mathrm{~kg} / \mathrm{m}^{3}$.

In order to observe and analyze the interface microstructures, the transverse cross sections of three-ply composite plates were cut parallel to the propagation direction of the detonating wave after EXW. The interface morphology was performed by a Tescan Mira 3 field emission scanning electron microscopy (SEM). The X-ray diffraction study was performed with a Rigaku Model Ultima IV X-ray diffractometer. Microstructures were observed by a Leica 2700M optical microscope (OM). The shear specimen was machined by a wire cut electric discharge machine along the explosive direction based on the GB/T6396-2008. The schematic diagram of shear test is shown in Figure 2. The shear area was fixed as $10 \mathrm{~mm} \times 10$ $\mathrm{mm}$ and the shear test were carried out at room temperature with speed of $0.5 \mathrm{~mm} / \mathrm{min}$ by using an electronic universal testing machine (mode ZWICK-Z020). The shear stress, $\tau$, is obtained from the formula, as follows:

$$
\tau=\frac{P}{a b}
$$

where $a$ and $b$ are the width and height of shear interface, respectively. They are assigned the same value of $10 \mathrm{~mm}$.

The hot rolling sample with the dimensions of $30 \times 70$ $\mathrm{mm}^{2}$ was heated at $400^{\circ} \mathrm{C}$ for five minutes primarily and then rolled with the reduction of $30 \%$ per step. Annealing was performed at $200^{\circ} \mathrm{C}, 300^{\circ} \mathrm{C}$ and $400^{\circ} \mathrm{C}$ for $1 \mathrm{~h}$ and $2 \mathrm{~h}$. Then the metallographic samples were prepared along the direction perpendicular to the rolling direction. The thickness of diffusion layer of the rolled samples under various annealing conditions was measured by the energy dispersive spectroscope (EDS). Moreover, the tensile experiments were performed. Dog-bone-shaped tensile specimens with a gage length of 10 $\mathrm{mm}$ were cut from the roll-bonded composite plates along rolling direction. The schematic of tensile specimen is given in Figure 3. The tensile tests were performed on universal material testing machine with a nominal strain rate of $10^{-3} \mathrm{~s}^{-1}$ at room temperature. The tensile fracture morphology was observed by SEM equipped with an EDS.

\section{Results and Discussion}

\subsection{Characterization of bonding interface}

Different morphology with big waveform and mini waveform is present in the explosively bonded interface without cracks and localized melting as shown in Figure $4 \mathrm{a}$ and $\mathrm{c}$. The formation of wavy morphology is deemed as one of the indicators of sound joints ${ }^{26}$. Vaidyanathan et $a l .{ }^{27}$ have explained that the formation of wavy morphology should be created to obtain optimum weld strength and mechanical interlocking. Cheng et al. ${ }^{28}$ attributed the wave 
Table 1. Chemical composition of experiment materials used in this study (mass \%).

\begin{tabular}{lcccccccc}
\hline Materials & $\mathrm{Zn}$ & $\mathrm{Mn}$ & $\mathrm{Fe}$ & $\mathrm{Cu}$ & $\mathrm{Si}$ & $\mathrm{Mg}$ & $\mathrm{Al}$ \\
\hline AZ31B & 1.10 & 0.63 & 0.005 & - & 0.10 & Rest & 3.02 \\
AA6061 & 0.23 & 0.10 & 0.60 & 0.20 & 0.50 & 0 & Rest \\
\hline
\end{tabular}

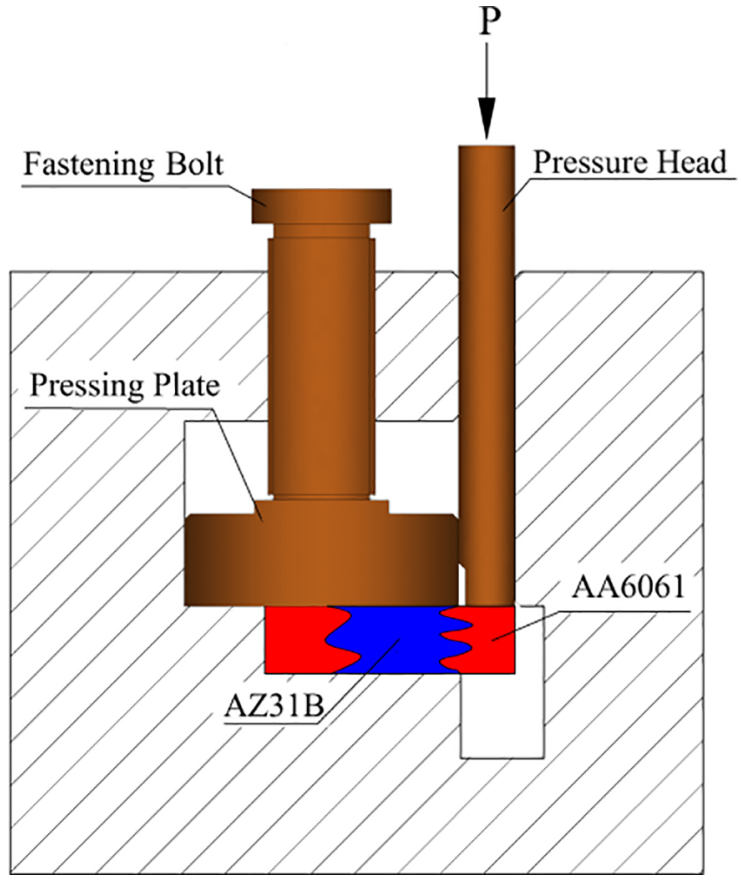

Figure 2. The schematic diagram of the shear test.
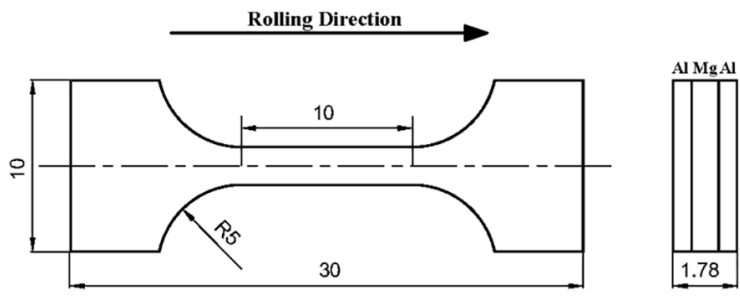

Figure 3. Schematic representation of tensile test specimen.

morphology to high interface shear-rate deformation or a shear plastic flow instability between two components. Figure $4 \mathrm{~b}$ and $d$ presents the enlarged micrographs of the interfaces. The thickness of diffusion layer was approximately $2.1 \mu \mathrm{m}$ for the big waveform side and $3.8 \mu \mathrm{m}$ for the mini waveform side indicating that elemental diffusion occurred at both sides. Besides, no any trace of IMC was observed macroscopically. Chen et al. ${ }^{29}$ indicated that a jet was formed in the circumstance of high temperature and pressure near the collision point penetrated the bonding interface and then the thin diffusion layer of interdiffusion with $\mathrm{Al}$ and $\mathrm{Mg}$ elements was promoted. Findik et al. ${ }^{9}$ reported that the EXW used explosive force to create an electron-sharing metallurgical bonding between two metal components, which was deemed as a solid-state metal joining process.
Zhang et al. ${ }^{7}$ reported similar results that the thin diffusion layer was formed in the $\mathrm{Al} / \mathrm{Mg}$ composites.

The results of X-ray diffraction at both interfaces are shown in Figure 5, which clearly pointed that the peaks of IMC phases were not detected indicating that there was no or a small amount of IMC generation at the bonding interface. Generally speaking, the prompt welding is characteristic of the EXW, and the welding between two metals is achieved in about $10^{-6} \mathrm{~s}$. Therefore, there is not enough time to form IMC at the bonding interface. Chen et al. ${ }^{29}$ analyzed the bonding interfaces of $\mathrm{Al} / \mathrm{Mg}$ EXWed composites using the transmission electron microscopy. The results indicated that the diffusion layer with the thickness of approximately $3 \mu \mathrm{m}$ was formed and no any trace of IMC was detected in the bonding interface. Yan et al. ${ }^{25}$ also reported the similar results that the sound joint was obtained and no IMC was observed in the bonding interface of $\mathrm{Al} / \mathrm{Mg}$ composites.

\subsection{Microstructure of constituent AZ31B of three-ply Al/Mg/Al composite plates after explosive welding}

Optical micrographs of the $\mathrm{Al} / \mathrm{Mg} / \mathrm{Al}$ composite plates on AZ31B magnesium alloy side after EXW are given in Figure 6 . It can be seen that the adiabatic shear bands (ASB) near the interface appears inclined about $45^{\circ}$ to the explosive direction from Figure $6 \mathrm{a}$ and $\mathrm{b}$. They originated from the interface and disappeared in the AZ31B magnesium alloy. The explosive could produce a circumstance of high temperature, high pressure and high strain rate near the collision point, which led to an adiabatic process. Then, ASB came into being. The same phenomenon was exhibited in the work of Zhang et al. ${ }^{30}$ This work indicated that stress waves were appeared owing to high energy accumulation induced the formation of ASB. Due to the drastic drop in temperature, however, the AZ31B magnesium alloys far away from the bonding interface were merely subjected to the high strain rate, which could induce the plastic deformation of $\mathrm{Mg}$ alloys by the activation of slip and twining. As shown in Figure $6 \mathrm{c}$, numerous twins were observed. Twinning is known to play a key role in the plastic deformation of magnesium alloys, which could alter the orientation of original grain, release the residual stress, reduce the nucleation of crack and influence the activation of slip systems. Hence, as a coordinating plastic deformation mechanism, twinning ensured the integrity of magnesium alloys plates under the high strain rate in the explosive process and contributed to the formation of bonding interface. 


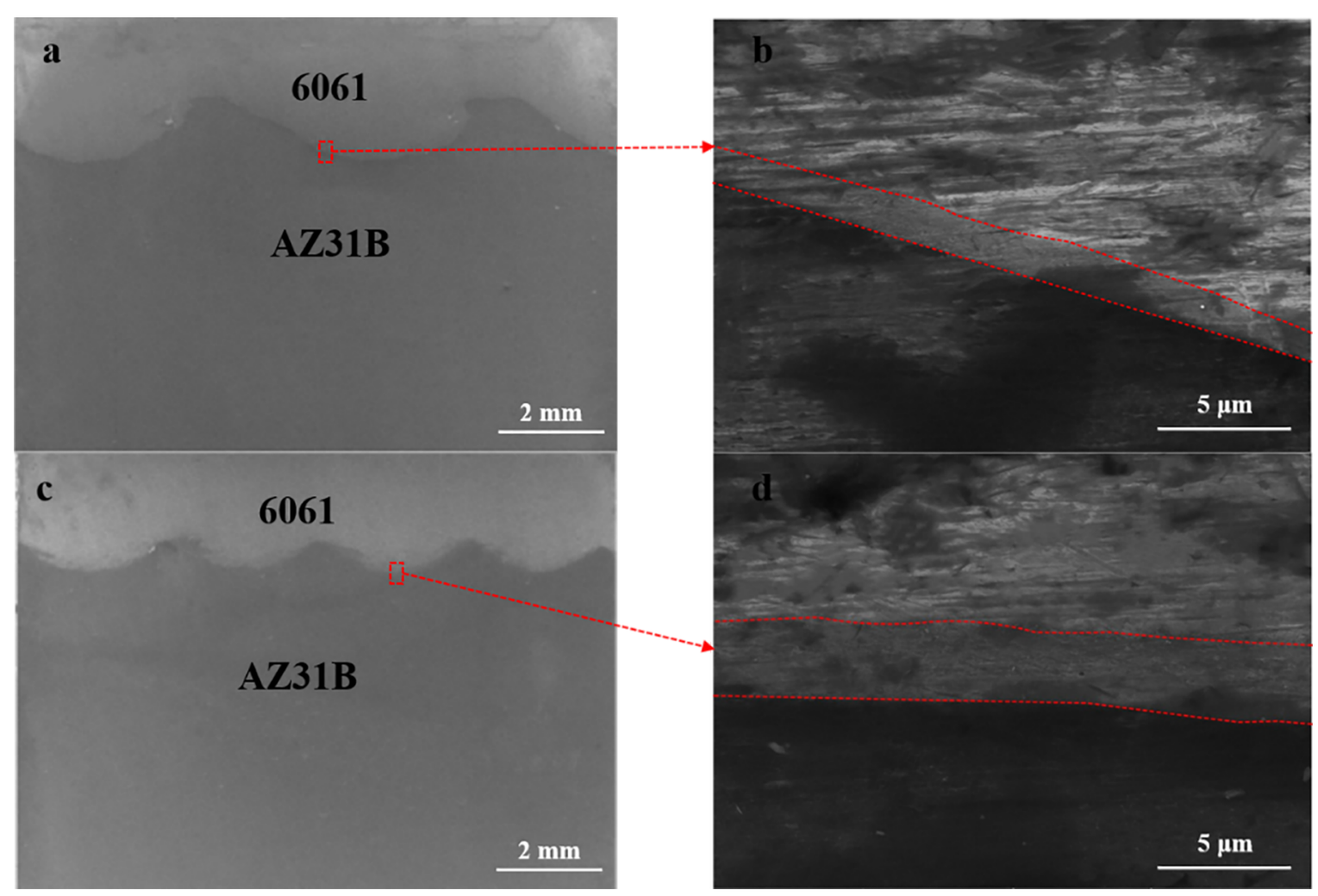

Figure 4. SEM images of the composite interfaces after explosive welding (a) big waveform (c) mini waveform.

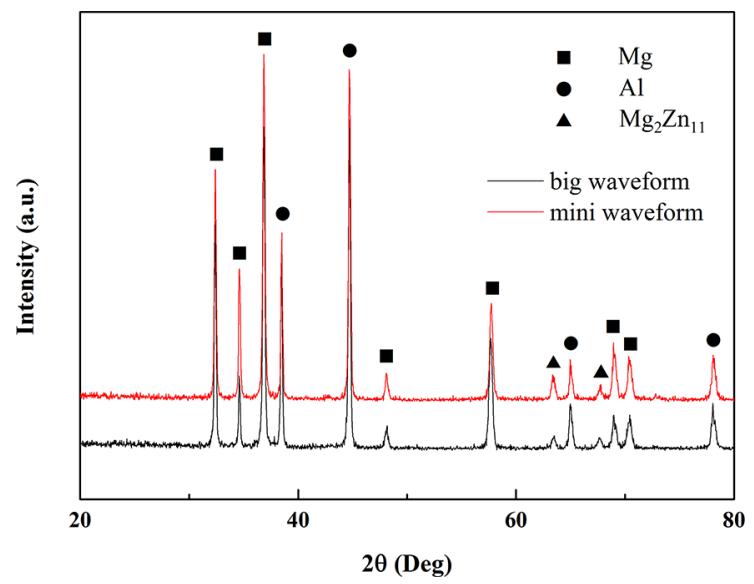

Figure 5. XRD patterns taken from the bonding interface.

\subsection{Evaluation of interface bonding strength of explosively welded composite plates}

In order to evaluate interface bonding strength of the three-ply composite plates fabricated by the EXW, the shear tests were conducted on the bonding interfaces of big waveform side and mini waveform side, respectively. The results indicated that shear strength of both sides shared similar values, which was $91 \mathrm{MPa}$ for big waveform side and 92MPa for mini waveform side. Comparing with the shear strength of Al/Mg composite plates fabricated by other methods such as diffusion welding ${ }^{31,32}$ and hot rolling ${ }^{33}$, the bonding interfaces of three-ply $\mathrm{Al} / \mathrm{Mg} / \mathrm{Al}$ composite plates fabricated by EXW shared considerable shear strength. Yan et al. ${ }^{25}$ exhibited that the shear strength of AZ31B/7075 composite plates was approximately $70 \mathrm{MPa}$ in the explosive welding process with a parallel layers arrangement. By comparison, the bonding interfaces of three-ply $\mathrm{Al} / \mathrm{Mg} / \mathrm{Al}$ composite plates in this study possessed higher bonding strength, which means that the vertical EXW process is feasible.

\subsection{The influence of hot rolling and annealing on the interface microstructures of the composite plates}

Figure 7 exhibits the interface microstructure of magnesium alloys in the rolled sample under various annealing conditions. Figure $7 \mathrm{a}$ is the microstructure of magnesium alloys in the rolled sample without annealing. It shows the typical nonuniform bimodal microstructure, fine grain sharing the submicrometer dimensions in comparison with the largest elongated grain with the size of $29.2 \mu \mathrm{m}$, indicating nonuniform deformation during hot rolling process. Figure $7 \mathrm{~b}$ is the OM images of the middle zone of Mg alloys obtained from rolled sample without annealing. Due to incomplete dynamic recrystallization in the process of hot rolling, a certain amount of fine recrystallization structure appeared. Figure 7c-e exhibits the optical micrographs of $\mathrm{Mg}$ alloys near the interface in the rolled samples annealed at different temperatures for $1 \mathrm{~h}$. Figure $7 \mathrm{c}$ and d shows small 


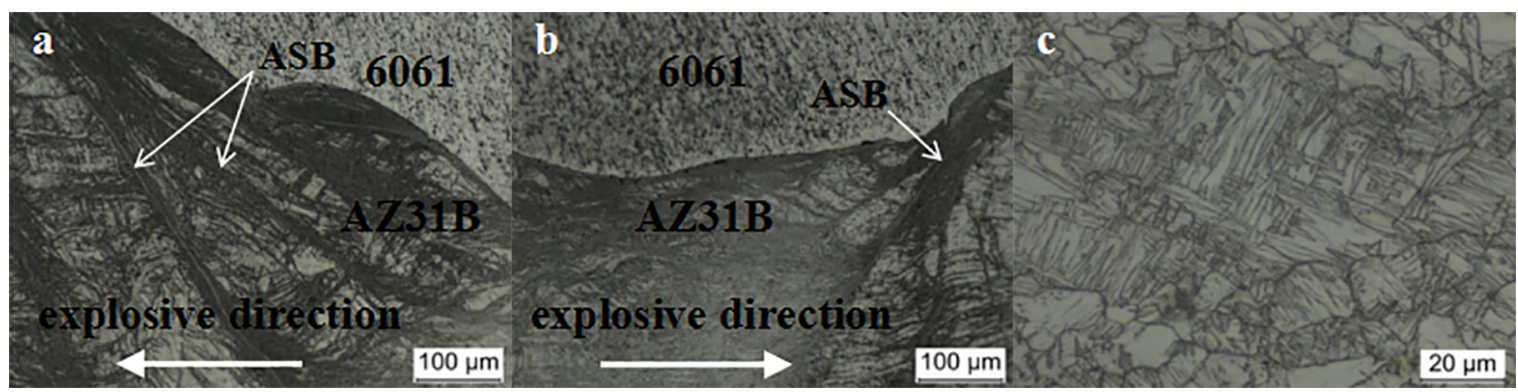

Figure 6. Optical micrographs obtained from (a) Mg alloys on the big waveform side (b) Mg alloys on the mini waveform side and (c) $\mathrm{Mg}$ alloys far away from the interface.

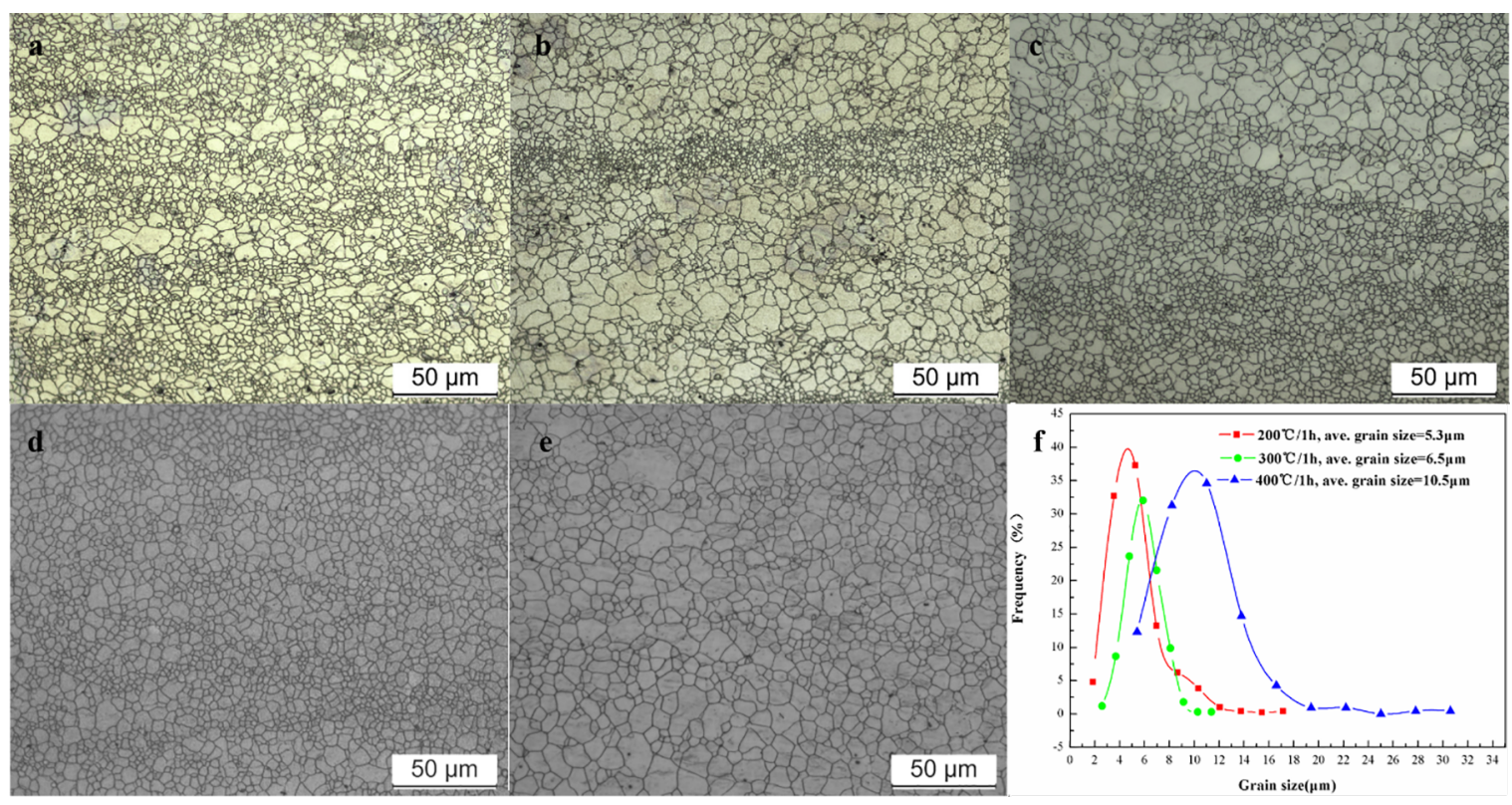

Figure 7. Microstructure of the Mg alloys of composite plates at different conditions: (a) near the interface of rolled sample without annealing, (b) far away from the bonding interface of rolled sample without annealing, (c) $200^{\circ} \mathrm{C} / 1 \mathrm{~h}$, (d) $300^{\circ} \mathrm{C} / 1 \mathrm{~h}$, (e) $400^{\circ} \mathrm{C} / 1 \mathrm{~h}$ and (f) Grain size distribution from (c to e).

and equiaxed grain due to static recovery process and the microstructure became accessibly homogenized. However, increasing annealing temperature could induce the rapid growth of grain as shown in Figure 7e. This implies that annealing temperature plays a key role in affecting the growth of magnesium alloy grain. The quantitative relationship between the grain size and heat treatment temperature are given in Figure 7f. It shows the grain size approximately obeys normal distribution and that the grain size increased with the increase of annealing temperature. The average grain size of $\mathrm{Mg}$ alloys annealing at $300^{\circ} \mathrm{C}$ for $1 \mathrm{~h}$ increased to $6.5 \mu \mathrm{m}$ whereas the counterpart of $\mathrm{Mg}$ alloys annealing at $200^{\circ} \mathrm{C}$ for $1 \mathrm{~h}$ is $5.3 \mu \mathrm{m}$. Besides, the grain size distribution of $300^{\circ} \mathrm{C}$ $/ 1 \mathrm{~h}$ is more homogenous. Furthermore, rapid increment of grain size occurred after annealing at $400^{\circ} \mathrm{C}$ for $1 \mathrm{~h}$ and the grain size distribution is disperse. The results indicated that the equiaxed and homogeneous grain morphology of magnesium alloys in the rolled samples was successfully induced by annealing $300^{\circ} \mathrm{C}$ for $1 \mathrm{~h}$.
Figure 8a is the thickness of diffusion layer of rolled composite plates under various annealing conditions. The thickness of diffusion layer was measured by the EDS. With the temperature and holding time increasing, the thickness of diffusion layer increased. However, the thickness of diffusion layer had no significant change with the increase of holding time at $200^{\circ} \mathrm{C}$ annealing condition. Then, as holding time increased from $1 \mathrm{~h}$ to $2 \mathrm{~h}$, the thickness of diffusion layer only slightly increased to about $5 \mu \mathrm{m}$ at $300^{\circ} \mathrm{C}$. However, under $400^{\circ} \mathrm{C}$ annealing condition the increase rate of thickness of diffusion layer increased rapidly with increase of holding time. Luo et al.$^{34}$ reported the similar phenomenon showing that the annealing temperature played a major role to increase the thickness of diffusion layer. The interdiffusion coefficient could be determined by the Arrhenius equation ${ }^{15}$,

$$
K=K_{0} \exp \left(-\frac{E}{R T}\right)
$$


where $K_{0}$ is the frequency factor $\left(\mathrm{m}^{2} / \mathrm{s}\right), E$ is the activation energy $(\mathrm{J} / \mathrm{mol}), \mathrm{R}(8.314 \mathrm{~J} / \mathrm{mol} \mathrm{K})$ is the gas constant and $\mathrm{T}$ is the absolute temperature in Kelvin $(\mathrm{K})$. It is seen that the interdiffusion coefficient increases with the increase of annealing temperature. This results in the increase of thickness of diffusion layer. The square of thickness of diffusion layer is linear with heat-treatment time for a multiphase diffusion layer ${ }^{15}$, which can be described as,

$$
\mathrm{y}^{2}=K t
$$

where $y$ is the thickness of diffusion layer, $K$ is the interdiffusion coefficient which is mentioned above, $t$ is the heat-treatment time. By substituting the expression of $K$ in the formula (2) into the equation (3), the function of the thickness of diffusion layer with annealing temperature and heat-treatment time is obtained, it can be described as,

$$
\mathrm{y}^{2}=K_{0} \exp \left(-\frac{E}{R T}\right) t
$$

The formula (4) shows the change law between the thickness of diffusion layer and the heat-treatment temperature and time. The square of thickness of diffusion layer exponentially increases when annealing temperature increases. Moreover, the square of thickness of diffusion layer is linear with heattreatment time. This indicates that the annealing temperature produces effect on the thickness of diffusion layer is greater than holding time, which could explain why the thickness of diffusion layer increased rapidly with increase of annealing temperature, as shown in Figure 8a. Figure $8 \mathrm{~b}$ exhibits the interface morphology of rolled sample annealing at $400^{\circ} \mathrm{C}$ for $1 \mathrm{~h}$. The interface presented two distinct diffusion layers and the thickness of two diffusion layers was significantly different. The elemental composition of two layers was measured by EDS. The results indicated that the layer close to the side of $\mathrm{Mg}$ alloys was $\mathrm{Mg}_{17} \mathrm{Al}_{12}$ and the layer close to the side of $\mathrm{Al}$ alloys was $\mathrm{Al}_{3} \mathrm{Mg}_{2}$. Qiao et al. ${ }^{35}$ reported that $\mathrm{Mg}_{17} \mathrm{Al}_{12}$ is easier to form than $\mathrm{Al}_{3} \mathrm{Mg}_{2}$ under the same conditions. However, the growth rate of $\mathrm{Al}_{3} \mathrm{Mg}_{2}$ is higher than that of $\mathrm{Mg}_{17} \mathrm{Al}_{12}$. This could explain why the $\mathrm{Al}_{3} \mathrm{Mg}_{2}$ layer is thicker than $\mathrm{Mg}_{17} \mathrm{Al}_{12}$ layer after annealing at $400^{\circ} \mathrm{C}$ for $1 \mathrm{~h}$, as shown in Figure $8 \mathrm{~b}$.

\subsection{Mechanical properties of composite plates annealed at different conditions}

Figure 9 displays the engineering stress-strain curves of composite plates at different states and their tensile properties are shown in Figure10. The rolled sample without annealing shared the high UTS value of $235 \mathrm{MPa}$. Stress state of the samples between the rolled and the explosive-welded is different, namely the rolled sample is in tensile mode and the explosive-welded sample is in shear mode. Based on the difference of loading mode, it can be assumed that shear strength is equivalent to $1 / \sqrt{3}$ of tensile strength for the same material ${ }^{25,36}$. Therefore, it can be concluded that the hot rolling further improved the bonding strength of composite plates compared with explosive welding. As shown in Figure 10, the UTS of rolled sample without annealing reached a maximum due to dynamic recrystallization and the increase of interfacial bonding strength arising from the

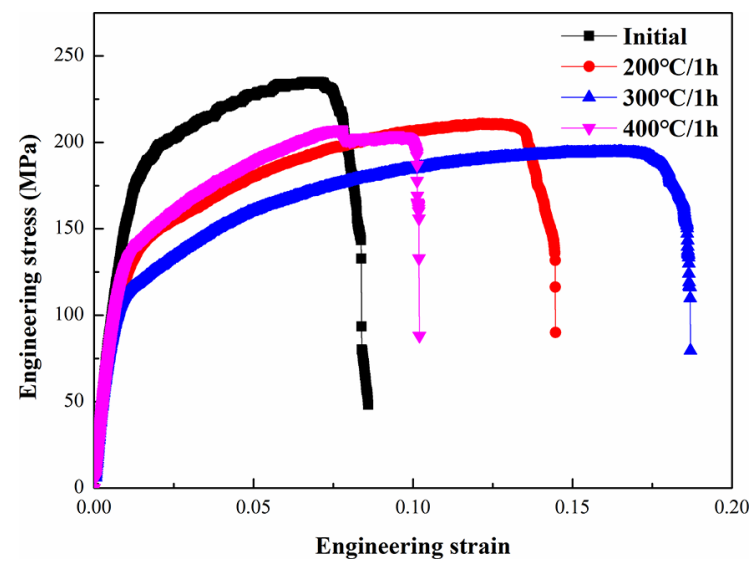

Figure 9. Engineering stress-strain curves of EXW + rolled composite plates annealed at different temperature for $1 \mathrm{~h}$.

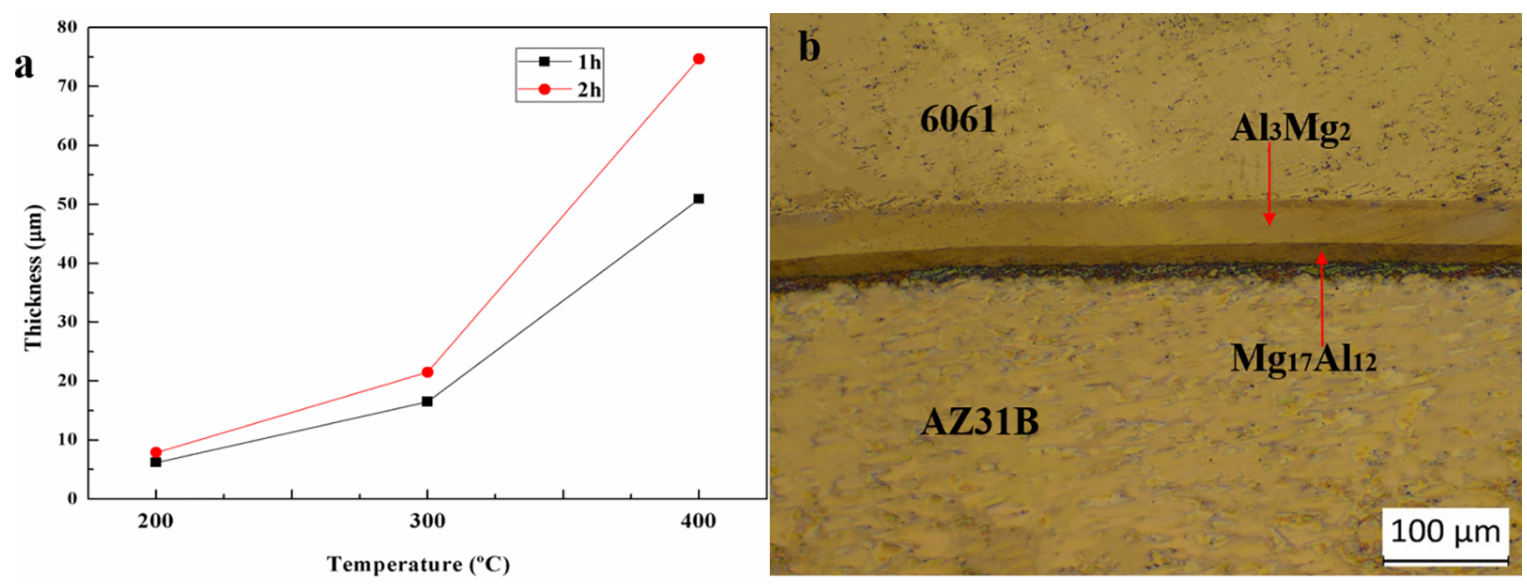

Figure 8. (a) The thickness of interface diffusion layer of rolled composite plates under various annealing conditions and (b) the interface morphology of rolled sample annealing at $400^{\circ} \mathrm{C}$ for $1 \mathrm{~h}$. 
onset of diffusion ${ }^{15}$. However, the elongation of rolled sample without annealing was only $8.5 \%$. In order to obtain good combination of relatively high plasticity and tensile strength, proper annealing is necessary. With the increase of annealing temperature, the elongation firstly increased from $200^{\circ} \mathrm{C}$ to $300^{\circ} \mathrm{C}$, reached a maximum value of $18.5 \%$ at $300^{\circ} \mathrm{C}$, then decreased from $300^{\circ} \mathrm{C}$ to $400^{\circ} \mathrm{C}$. The initial increase in elongation was attributed to softening effect which is caused by recovery and recrystallization. Considering the formability of thick Mg alloys is less than that of the thin Al alloys, the microstructures of $\mathrm{Mg}$ alloys have to be analyzed. Under $300^{\circ} \mathrm{C}$ annealing condition, the homogeneous microscopic morphology of $\mathrm{Mg}$ alloys was obtained, which was attributed to relatively homogeneous recrystallization. This conduced to the improvement of elongation. The subsequent decrease in the elongation may be attributed to interfacial debonding due to the rapid increment of diffusion layer which presented two distinct layers including $\mathrm{Al}_{3} \mathrm{Mg}_{2}$ layer and $\mathrm{Mg}_{17} \mathrm{Al}_{12}$ layer clearly, as shown in Figure 8. This could be confirmed by the tendency of sudden change of stress-strain curve at $400^{\circ} \mathrm{C}$ for 1h. Lee et al. ${ }^{17}$ reported that the diffusion layer exceeding a certain size affected plasticity of composites with a negative manner. Macwan et al. ${ }^{15}$ indicated that softening effect in the $\mathrm{Mg}$ and $\mathrm{Al}$ alloys by proper annealing at $300^{\circ} \mathrm{C}$ conduced to improve the elongation of composites. Accordingly, the rolled composites possessed good combination of relatively high plasticity and tensile strength after annealing $300^{\circ} \mathrm{C}$ for $1 \mathrm{~h}$.

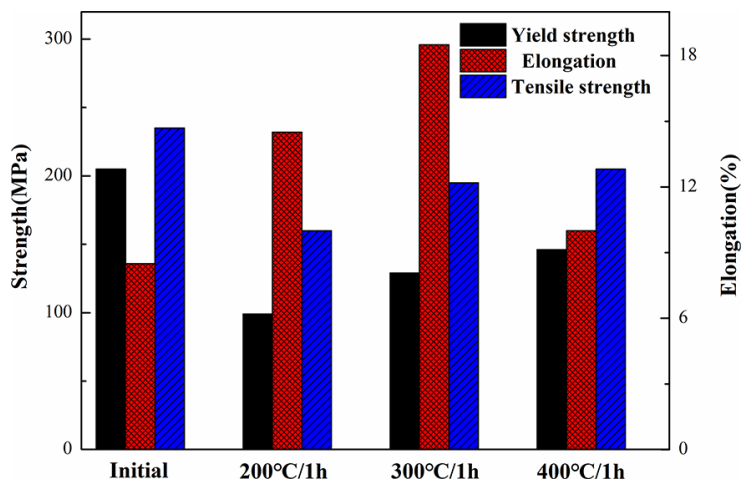

Figure 10. Tensile properties of rolled composite plates annealed at different temperature for $1 \mathrm{~h}$.
The fracture morphology of $\mathrm{Mg}$ alloys in the composites under different conditions was observed by $\mathrm{SEM}^{17}$. From Figure 11a, the rolled specimens without annealing exhibited the appearance of diminutive cleavage plane, tear ridge and a little cavity band, indicating that it is quasi-cleavage fracture. Because of the refinement and homogeneity of grain, a large amount of deep equal-axis dimple can be observed in Figure 11b. This is also implied that the annealing condition of $300^{\circ} \mathrm{C} / 1 \mathrm{~h}$ is applicable.

Figure 12 shows the interface fractography and EDS spectra from points marked $\mathrm{A}$ and $\mathrm{B}$ obtained from the rolled specimen annealed at $400^{\circ} \mathrm{C}$ for $2 \mathrm{~h}$. Layering phenomenon at $\mathrm{Mg}-\mathrm{Al}$ interface after uniaxial tension occurred and numerous fragments was scattered over the interlamination. EDS spectra results indicated that these fragments obtained from the diffusion layer were $\mathrm{Al}_{3} \mathrm{Mg}_{2}$ phase. Jafarian et al. ${ }^{37}$ demonstrated the brittle IMC, $\mathrm{Al}_{3} \mathrm{Mg}_{2}$ and $\mathrm{Al}_{12} \mathrm{Mg}_{17}$, were generated in the bonding interface and that the micro-hardness of $\mathrm{Al}_{3} \mathrm{Mg}_{2}$ was obviously higher than that of its $\mathrm{Al}_{12} \mathrm{Mg}_{17}$ counterpart. This is implied that $\mathrm{Al}_{3} \mathrm{Mg}_{2}$ layer is deemed to play the part of the origin of interface delamination and the zone of crack initiation.

\section{Conclusions}

In this study, thin three-ply $\mathrm{Al} / \mathrm{Mg} / \mathrm{Al}$ composite plates were achieved successfully through the process of vertical EXW and hot rolling. The interface microstructure and mechanical properties of the explosive-weld three-ply Al/Mg/Al composite plates before and after hot rolling were evaluated. The influence of annealing on the interface microstructure and mechanical properties of the thin EXWed-rolled composites was investigated. The following conclusions were drawn.

1. The vertical explosive welding process in this study is feasible to fabricate the three-ply $\mathrm{Al} / \mathrm{Mg}$ / $\mathrm{Al}$ composite plates and the sound joints between $\mathrm{Mg}$ alloys and $\mathrm{Al}$ alloys was obtained.

2. The explosively bonded interface presented big waveform and mini waveform and the shear strength of both sides shared similar values, which was $91 \mathrm{MPa}$ for big waveform side and 92MPa for mini waveform side.

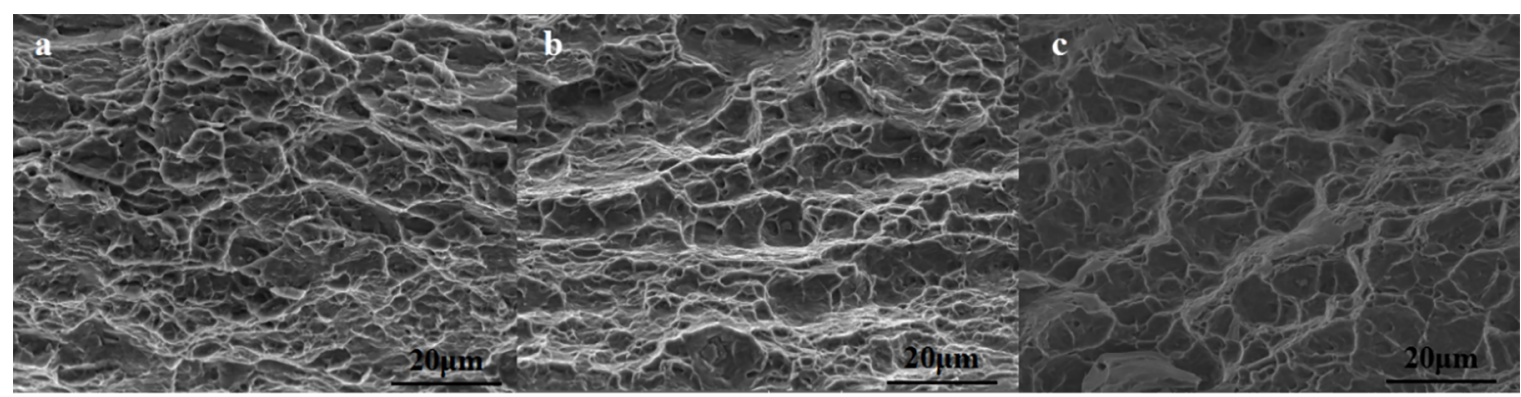

Figure 11. SEM images representing tensile fracture surface of AZ31B Mg alloys from the tensile test specimens annealed at (a) Rolled, (b) $300^{\circ} \mathrm{C} / 1 \mathrm{~h}$ and (c) $400^{\circ} \mathrm{C} / 1 \mathrm{~h}$. 


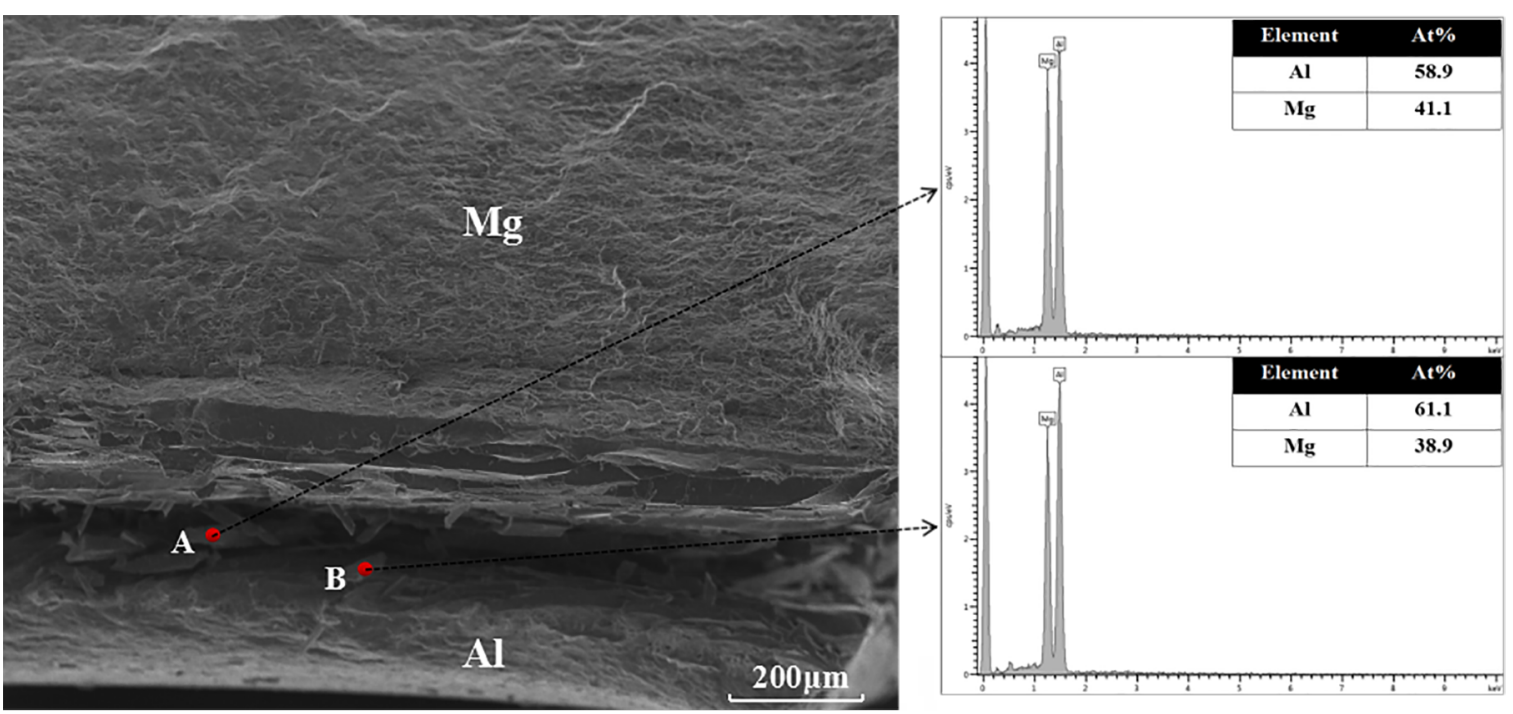

Figure 12. Interface fractograph obtained from the specimen annealed at $400^{\circ} \mathrm{C}$ for $2 \mathrm{~h}$ and EDS spectra from layers marked by letters $\mathrm{A}$ and $\mathrm{B}$.

3. Hot rolling conduced to improve the bonding strength of composite plates.

4. The thin three-ply $\mathrm{Al} / \mathrm{Mg} / \mathrm{Al}$ composite plates annealing at $300^{\circ} \mathrm{C} / 1 \mathrm{~h}$ possessed equiaxed and homogeneous grain morphology in the constituent AZ31 part and good combination of relatively high plasticity and tensile strength.

5. $\mathrm{Al}_{3} \mathrm{Mg}_{2}$ layer is the origin of interface delamination and the zone of crack initiation.

\section{Acknowledgments}

This study was financially supported by the Natural Science Foundation Project of China (51375328, 51704209) and the Research Project Supported by Shanxi Scholarship council of China (2015036, 2016021063).

\section{References}

1. Ashby MF, Bréchet YJM. Designing hybrid materials. Acta Materialia. 2003;51(19):5801-5821.

2. Jiang H, Yi Z, Cheng P, Kong C, Li M, Wang X, et al. Modified thermal resistance networks model for transverse thermal conductivity of unidirectional fiber composite. Composites Communications. 2017;6:52-58.

3. Zahra T, Dhanasekar M. Characterisation of cementitious polymer mortar - Auxetic foam composites. Construction and Building Materials. 2017;147:143-159.

4. Stankovic T, Mueller J, Shea K. The effect of anisotropy on the optimization of additively manufactured lattice structures. Additive Manufacturing. 2017;17:67-76.

5. Ashby M. Designing architectured materials. Scripta Materialia. 2013;68(1):4-7.
6. Nie H, Liang W, Chi C, Li X, Fan H, Yang F. Effect of Annealing on Microstructure and Tensile Properties of 5052/AZ31/5052 Clad Sheets. JOM. 2015;68(5):1282-1292.

7. Zhang N, Wang W, Cao X, Wu J. The effect of annealing on the interface microstructure and mechanical characteristics of AZ31B/ AA6061 composite plates fabricated by explosive welding. Materials \& Design (1980-2015). 2015;65:1100-1109.

8. Wang D, Cao X, Wang L, Cao M, Wang W. Influence of hot rolling on the interface microstructure and mechanical properties of explosive welded $\mathrm{Mg} / \mathrm{Al}$ composite plates. Journal of Materials Research. 2017;32(4):863-873.

9. Findik F. Recent developments in explosive welding. Materials \& Design. 2011;32(3):1081-1093.

10. Dugal F, Ciappa M. Reliability investigation of the copper-zinc system for solid diffusion bonding in power modules. Microelectronics Reliability. 2017;76-77:460-464.

11. Joseph Fernandus M, SenthilkumarT, Balasubramanian V, Rajakumar S. Optimising diffusion bonding parameters to maximize the strength ofAA6061 aluminium and AZ31B magnesium alloy joints. Materials \& Design. 2012;33:31-41.

12. Liu F, Ren D, Liu L. Effect of Al foils interlayer on microstructures and mechanical properties of $\mathrm{Mg}$-Al butt joints welded by gas tungsten arc welding filling with Zn filler metal. Materials \& Design . 2013;46:419-425.

13. Spencer K, Zhang MX. Heat treatment of cold spray coatings to form protective intermetallic layers. Scripta Materialia. 2009;61(1):44-47.

14. Lee KS, Lee SE, Sung HK, Lee DH, Kim JS, Chang YW, et al. Influence of reduction ratio on the interface microstructure and mechanical properties of roll-bonded Al/Cu sheets. Materials Science and Engineering: A. 2013;583:177-181.

15. Macwan A, Jiang XQ, Li C, Chen DL. Effect of annealing on interface microstructures and tensile properties of rolled $\mathrm{Al} / \mathrm{Mg} /$ $\mathrm{Al}$ tri-layer clad sheets. Materials Science and Engineering: $A$. 2013;587:344-351. 
16. Lee KS, Yoon DH, Kim HK, Kwon YN, Lee YS. Effect of annealing on the interface microstructure and mechanical properties of a STS-Al-Mg 3-ply clad sheet. Materials Science and Engineering: A. 2012;556:319-330.

17. Lee KS, Kim JS, Jo YM, Lee SE, Heo J, Chang YW, et al. Interface-correlated deformation behavior of a stainless steel-Al-Mg 3-ply composite. Materials Characterization. 2013;75:138-149.

18. Kahraman N, Gulenc B, Findik F. Corrosion and mechanicalmicrostructural aspects of dissimilar joints of Ti-6Al-4V and Al plates. International Journal of Impact Engineering. 2007;34(8):1423-1432.

19. Hong X, Godfrey A, Liu W, Orozco-Caballero A, da Fonseca JQ. Effect of pre-existing twinning on strain localization during deformation of a magnesium alloy. Materials Letters. 2017;209:94-96.

20. Lu Y, Bradshaw AR, Chiu YL, Jones IP. Effects of secondary phase and grain size on the corrosion of biodegradable $\mathrm{Mg}-\mathrm{Zn}-\mathrm{Ca}$ alloys. Materials Science and Engineering: C. 2015;48:480486.

21. Asemabadi M, Sedighi M, Honarpisheh M. Investigation of cold rolling influence on the mechanical properties of explosivewelded Al/Cu bimetal. Materials Science and Engineering: A. 2012;558:144-149.

22. Fronczek DM, Wojewoda-Budka J, Chulist R, Sypiena A, Korneva A, Szulc Z, et al. Structural properties of Ti/Al clads manufactured by explosive welding and annealing. Materials \& Design. 2016;91:80-89.

23. Bae JH, Prasada Rao AK, Kim KH, Kim NJ. Cladding of $\mathrm{Mg}$ alloy with $\mathrm{Al}$ by twin-roll casting. Scripta Materialia. 2011;64(9):836-839.

24. Fronczek DM, Chulist R, Litynska-Dobrzynska L, Kac S, Schell N, Kania Z, et al. Microstructure and kinetics of intermetallic phase growth of three-layered A1050/AZ31/A1050 clads prepared by explosive welding combined with subsequent annealing. Materials \& Design. 2017;130:120-130.

25. Yan YB, Zhang ZW, Shen W, Wang JH, Zhang LK, Chin BA. Microstructure and properties of magnesium AZ31B-aluminum 7075 explosively welded composite plate. Materials Science and Engineering: A. 2010;527(9):2241-2245.

26. Duan M, Yang X, Feng K, Wei L, Wang Y. Experimental investigation of explosive weld of bimetal ribbed plate based on boss charging. Fusion Engineering and Design. 2018;129:294299.
27. Vaidyanathan PV, Ramanathan AR. Design for quality explosive welding. Journal of Materials Processing Technology. 1992;32(1-2):439-448.

28. Cheng C, Tan Q. Mechanism of wave formation at the interface in explosive welding. Acta Mechanica Sinica. 1989;5(2):97-108.

29. Chen P, Feng J, Zhou Q, An E, Li J, Yuan Y, et al. Investigation on the Explosive Welding of 1100 Aluminum Alloy and AZ31 Magnesium Alloy. Journal of Materials Engineering and Performance. 2016;25(7):2635-2641.

30. Zhang T, Wang W, Zhang W, Wei Y, Cao X, Yan Z, et al. Microstructure evolution and mechanical properties of an AA6061/AZ31B alloy plate fabricated by explosive welding. Journal of Alloys and Compounds. 2018;735:1759-1768.

31. Zhao LM, Zhang ZD. Effect of Zn alloy interlayer on interface microstructure and strength of diffusion-bonded Mg-Al joints. Scripta Materialia. 2008;58(4):283-286.

32. Seyyed Afghahi SS, Jafarian M, Paidar M, Jafarian M. Diffusion bonding of A1 7075 and Mg AZ31 alloys: Process parameters, microstructural analysis and mechanical properties. Transactions of Nonferrous Metals Society of China. 2016;26(7):1843-1851.

33. Zhang XP, Yang TH, Castagne S, Wang JT. Microstructure; bonding strength and thickness ratio of $\mathrm{Al} / \mathrm{Mg} / \mathrm{Al}$ alloy laminated composites prepared by hot rolling. Materials Science and Engineering: A. 2011;28(4-5):1954-1960.

34. Luo C, Liang W, Chen Z, Zhang J, Chi C, Yang F. Effect of high temperature annealing and subsequent hot rolling on microstructural evolution at the bond-interface of $\mathrm{Al} / \mathrm{Mg}$ / $\mathrm{Al}$ alloy laminated composites. Materials Characterization. 2013;84:34-40.

35. Qiao X, Li X, Zhang X, Chen Y, Zheng M, Golovin IS, et al. Intermetallics formed at interface of ultrafine grained $\mathrm{Al} / \mathrm{Mg}$ bi-layered disks processed by high pressure torsion at room temperature. Materials Letters. 2016;181:187-190.

36. Borrisutthekul R, Miyashita Y, Mutoh Y. Dissimilar material laser welding between magnesium alloy AZ31B and aluminum alloy A5052-O. Science and Technology of Advanced Materials. 2016;6(2):199-204.

37. Jafarian M, Rizi MS, Jafarian M, Honarmand M, Javadinejad HR, Ghaheri A, et al. Effect of thermal tempering on microstructure and mechanical properties of Mg-AZ31/A16061 diffusion bonding. Materials Science and Engineering: A. 2016;666:372-379. 